\section{AVALIAÇÃO DE IMPACTO AMBIENTAL EM NASCENTES DO ALTO CAMAQUÃ A PARTIR DE UMA ANÁLISE MULTIVARIADA}

\section{RESUMO}

Devido à carência de sistemas de captação de água no território do Alto Camaquã, a utilização direta de nascentes como fonte de água tornou-se a solução mais viável para o abastecimento humano e dessedentação animal. Localizada a montante da Bacia hidrográfica do Camaquã, o controle desenfreado dos usos destes afloramentos ocasiona impactos, podendo comprometer a dinâmica do ciclo hidrológico, visto que, geologicamente, a região é pouco favorável para poços tubulares. Diante deste panorama, o presente artigo tem como objetivo descrever a tipologia das nascentes, classificar e caracterizar seu estado, utilizando um protocolo de avaliação rápida, adaptado ao contexto do Alto Camaquã, para avaliar o impacto ambiental causado com base nas variáveis observadas. Foi feito um levantamento das características, tipologia e classificação das nascentes, nos distritos Barrocão, Alto Bonito e Aberta do Cerro, municípios de Piratini e Pinheiro Machado/RS. Foi analisada a relação entre essas características por meio de estatística multivariada, para subsidiar a avaliação de impactos ambientais. Foram realizadas análise de ordenação (coordenadas principais) e de agrupamentos. Identificou-se que na área delimitada existem três grupos de nascentes significativamente dissimilares e que a formação desses agrupamentos demonstram a relação entre as características e o tipo de uso das nascentes. Verificou-se uma diferenciação entre as nascentes com maior e menor impacto ambiental. Os resultados demonstram a necessidade de políticas de gestão e educação, bem como de metodologias diferenciadas de avaliação de impactos para os diferentes grupos identificados de nascentes, a fim de ser alcançada maior eficiência e conservação das mesmas.

PALAVRAS-CHAVES: Alto Camaquã; Território; Água.

\section{FOR ENVIRONMENTAL IMPACT ASSESSMENT ON THE SPRINGS OF THE TERRITORY OF THE ALTO CAMAQUÃ THROUGH A MULTIVARIATE ANALYSIS}

\section{ABSTRACT}

Due to the lack of water harvesting systems in the territory of Alto Camaquã, the direct use of springs as a water source has become the most feasible solution for human and animal consumption. Located upstream of the Camaquã Watershed, the unbridled control of the uses of these outcrops causes impacts and may affect the dynamics of the hydrological cycle, seen that, geologically, the region is unfavorable for wells. Faced with this panorama, this article aims to describe the types of sources, classify and characterize its state using a protocol for rapid assessment, adapted to the context of the Alto Camaquã, to assess the environmental impact based on the observed variables. A survey of the characteristics, typology and classification of springs was done, in the districts of Barrocão, Alto Bonito and Aberta do Cerro, municipalities of Piratini and Pinheiro Machado/RS. It was analyzed the relationship between these characteristics by multivariate statistics, to support the assessment of environmental impacts. Ordination analysis (principal coordinates) and clusters were performed. It was found that in the defined area there are three groups of significantly dissimilar springs and that the formation of such groups show the relationship between the characteristics and type of use of the springs. There was a distinction between the sources with higher and lower environmental impact. The results demonstrate the necessity for policy of management and education, as well as different methodologies for impact assessment for the different identified groups of springs, to achieve greater efficiency and conservation thereof.

KEYWORDS: Alto Camaquã; Territory; Water. v.6, n.1, Dez 2014, Jan, Fev, Mar, Abr, Mai 2015.

ISSN 2179-6858

\section{SECTION: Articles}

TOPIC: Recursos Hídricos

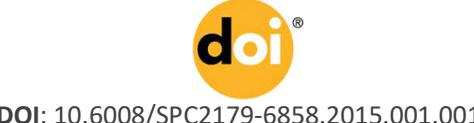

DOI: 10.6008/SPC2179-6858.2015.001.0016

Cibelle Machado Carvalho

Universidade Federal de Santa Maria, Brasil http://lattes.cnpq.br/5235132116415726

cibellemc@yahoo.com.br

Anderson da Silva Lucas

Universidade Estadual do Oeste do Paraná, Brasil http://lattes.cnpq.br/3558957913415281

andersonluks@hotmail.com

Nájila Souza da Rocha

Universidade Federal de Santa Maria, Brasil http://lattes.cnpq.br/3620150074460954

najila.rocha2011@gmail.com

Rafael Cabral Cruz

Universidade Federal do Pampa, Brasil http://lattes.cnpq.br/1246969166762146 rafaelcabralcruz@gmail.com

Marcos Flávio da Silva Borba Embrapa Pecuária Sul, Brasil marcos.borba@embrapa.br

Received: 19/07/2014

Approved: 14/10/2015

Reviewed anonymously in the process of blind peer

\section{Referencing this:}

CARVALHO, C. M.; LUCAS, A. S.; ROCHA, N. S.; CRUZ, R. C.; BORBA, M. F. S.. Avaliação de impacto ambiental em nascentes do Alto Camaquã a partir de uma análise multivariada. Revista lbero-Americana de Ciências Ambientais, Aquidabã, v.6, n.1, p.202-212, 2015. DOI: http://dx.doi.org/10.6008/SPC2179- 


\section{INTRODUÇÃO}

A Metade Sul do Rio Grande do Sul (RS), em geral, e o território do Alto Camaquã, em particular, localizado na região situada na porção mais a montante da Bacia do Rio Camaquã, constituem um espaço geográfico onde o desenvolvimento sócio-econômico não obteve o mesmo desempenho como o alcançado na Metade Norte do Rio Grande do Sul (ROCHA, 2011). discurso do (sub) desenvolvimento foi incorporado pelas populações locais que ainda hoje reproduzem a noção de incapacidade, algo que fica expresso nas estratégias de desenvolvimento regional pautadas por iniciativas desenhadas, implantadas e controladas de 'fora-para-dentro', sem qualquer participação da população local que a tudo assiste passivamente (BORBA, 2009).

Neste contexto, a inserção de monoculturas de árvores exóticas, soja, etc., justificam-se pela necessidade de se obterem níveis de produção que superem a improdutividade dos recursos naturais. Resta uma profunda preocupação com a evolução da paisagem e a construção de cenários futuros deste território (FIGUEIRÓ et al., 2011). A sub-bacia do Alto Camaquã, por estar inserida no Bioma Pampa, revela ainda uma combinação particular de elementos abióticos com uma diversidade biológica muito presente, sendo a associação destas características responsável por uma beleza paisagística inusitada. Assim, as particularidades da paisagem encontrada no Alto Camaquã revelam a existência de um grande patrimônio natural e histórico-cultural a ser preservado.

Alto Camaquã tem a pecuária familiar como a sua principal forma de produção campesina. Os pecuaristas têm uma relação muito intensa com o meio ambiente, estabelecendo uma interdependência entre a sua pequena produção e os recursos naturais. As atividades no meio rural necessitam estar em harmonia com a conservação do meio ambiente, uma vez que utilizam os recursos naturais de forma direta para sustentar seus processos. Porém, a geologia do sistema de aquíferos da Serra do Sudeste do Estado do Rio Grande do Sul é predominantemente fraturada e com baixa ocorrência de aquíferos porosos, o que torna a região pouco favorável para o atendimento da demanda hídrica a partir do uso de poços tubulares (LUCAS, 2013).

A partir desta limitação, os pecuaristas do território utilizam as nascentes como fonte produtora de água. A população do Alto Camaquã aplica o conhecimento empírico para a construção de reservatórios, popularmente conhecidos na região como 'cacimbas', e dos meios técnicos e financeiros que dispõe para construção de um sistema de distribuição de água. Porém, como há ausência de saneamento básico, depósitos de resíduos próximos aos pontos de afloramento, utilização da terra nas áreas de recarga e as características naturais da região que regem a dinâmica deste corpo hídrico, podem influenciar na quantidade e na qualidade da água ofertada.

A partir desta problemática, descrever a tipologia das nascentes, classificar e caracterizar seu estado, utilizando um protocolo de avaliação rápida, adaptado ao contexto do Alto Camaquã, para avaliar o impacto ambiental causado com base nas variáveis observadas, para subsidiar 
futuras formulações de projetos de educação hídrica adequadas para o território do Alto Camaquã.

\section{REVISÃO TEÓRICA}

\section{Alto Camaquã e Suas Fragilidades}

O estudo foi desenvolvido na região do Alto Camaquã, terço superior da bacia hidrográfica do Rio Camaquã (figura 2). Os estudos concentraram-se nos municípios de Pinheiro Machado e Piratini, especificamente nos distritos do Barrocão, Alto Bonito e Aberta do Cerro, localizados na Serra do Sudeste, Metade Sul do Rio Grande do Sul. Esta região está inserida no Bioma Pampa e caracteriza-se por ser um mosaico de vegetação campestre e arbustiva (FIGUEIRÓ, 2011). O Alto Camaquã apresenta um excelente estado de conservação da cobertura vegetal natural, tendo em vista a predominância das formações campestres e florestas naturais (TRINDADE et al., 2010).

O Alto Camaquã está localizado na região do Escudo Cristalino Sul-Rio-Grandense (FIGUEIRÓ, 2011). Apresenta um relevo montanhoso e bastante acidentado composto por formações rochosas graníticas, metamórficas e estruturas areníticas, além de solos rasos e pedregosos, pouco produtivos no contexto da agricultura. Estas características geológicas associam-se diretamente com a configuração hidrológica da região. Os contornos do terreno influenciam na formação de córregos e arroios, bem como na própria Bacia Hidrográfica do Rio Camaquã (figura 1). A geologia não influencia apenas os corpos hídricos superficiais, mas, também, a formação dos reservatórios subterrâneos. O conhecimento da geologia da região é basal na avaliação dos sistemas aquíferos, podendo-se entender a potencialidade da disponibilidade hídrica dos reservatórios através dos estudos hidrogeológicos.

Segundo Kirchheim e Agra (2011), a melhor classificação para o levantamento das potencialidades das águas subterrâneas do Estado é a do Mapa Hidrogeológico do Rio Grande do Sul, onde o sistema de aquíferos da região do Alto Camaquã é classificado como: "limitado de baixa possibilidade em rochas com porosidade intergranular ou por fraturas" e "improdutivos em rochas com porosidade intergranular ou por fraturas". A partir desta análise pode-se compreender que a construção de poços tubulares não seria a melhor alternativa para o abastecimento doméstico e animal, assim como para a irrigação.

A nascente, como fonte de água, é ideal para o ambiente rural, pois geralmente oferece água de boa qualidade, abundante e contínua, localizada próxima do local de uso e permitindo sua distribuição por gravidade, quando localizada em cota topográfica elevada, sem gasto de energia (CALHEIROS et al., 2004).

A construção de reservatórios junto às nascentes não estabelece um padrão e é feita de acordo com os recursos financeiros e conhecimento empírico dos pecuaristas familiares e com o alcance da funcionalidade desejada para o sistema de captação e distribuição de água 
(CARVALHO, 2013; LUCAS 2013). Para a construção destes reservatórios, muitas vezes, há uma supressão da vegetação nativa e interrompe-se o fluxo de água originado nas nascentes, o que pode acarretar problemas ambientais (Figura 1).

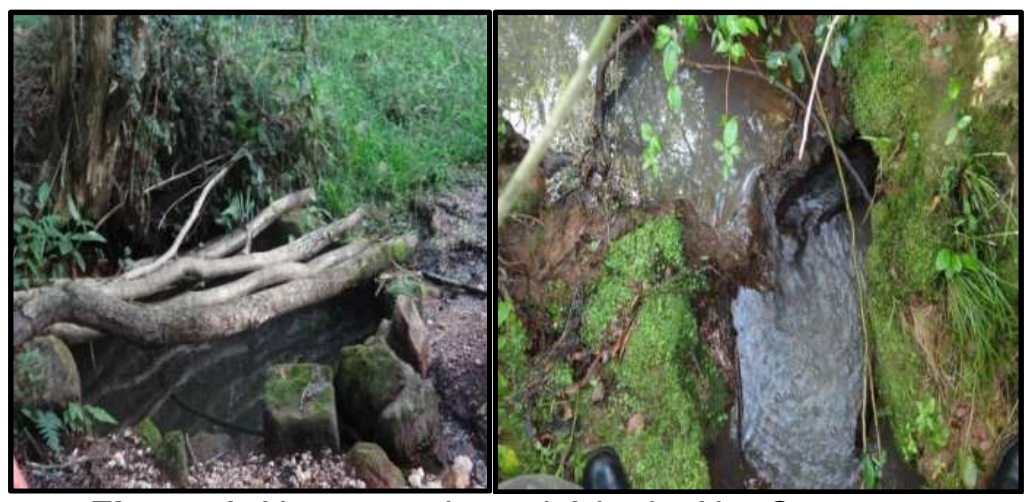

Figura 1: Nascente do território do Alto Camaquã.

A captação da água subterrânea de uma determinada bacia hidrográfica deve ser feita de forma controlada, pois poderá causar a redução dos fluxos de base dos seus rios, cujas consequências sociais, ambientais e econômicas podem ser muito sérias (REBOUÇAS, 2001). Além disso, a falta de um planejamento para um sistema de abastecimento pode levar a contaminação da água, enfraquecendo ou destruindo os ecossistemas naturais que sustentam a saúde humana, a produção alimentar e a biodiversidade (ONU, 2013). Portanto, um planejamento para a utilização dos recursos hídricos em uma estratégia de desenvolvimento territorial deve ser realizado para que uma das premissas desse tipo de desenvolvimento, o uso racional dos recursos naturais, seja respeitada.

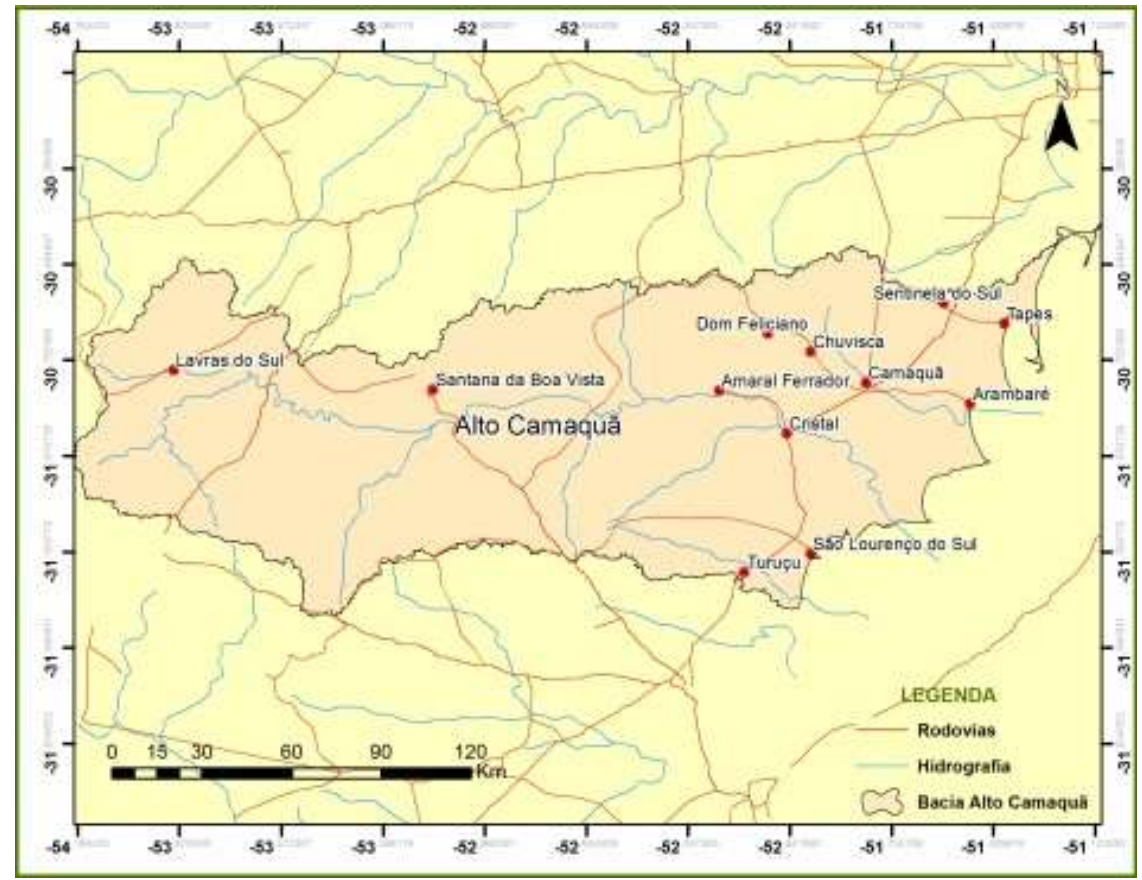

Figura 2: Bacia Hidrográfica do Rio Camaquã. 


\section{As Nascentes e a Gestão dos Recursos Hídricos do Território do Alto Camaquã}

Segundo o Plano de Gestão de Recursos Hídricos do Estado do Rio Grande do Sul é objetivo fundamental indicar áreas com problemas de escassez ou conflito, garantir a participação efetiva da sociedade, assegurando o crescimento econômico e social do Estado (SEMA, 2010). A Lei 9.433/97 que trata sobre a Política Nacional dos Recursos Hídricos (BRASIL, 1997), baseia-se nos seguintes fundamentos: a gestão dos recursos hídricos deve sempre proporcionar o uso múltiplo das águas e deve contar com a participação do Poder Público, dos usuários e das comunidades e assegurar para a atual e às futuras gerações a necessária disponibilidade de água em padrões de qualidade adequados, prevenir e defender a sociedade contra eventos hidrológicos críticos de origem natural ou decorrentes do uso inadequado dos recursos naturais.

A Lei n 10.350/94 (RIO GRANDE DO SUL, 1994) institui o Sistema Estadual de Recursos Hídricos da Constituição do Estado do Rio Grande do Sul, na qual o Art. 31 estabelece que - são dispensados da outorga os usos de caráter individual para satisfação das necessidades básicas da vida, assim, o uso humano, dessedentação de animais e a conservação ambiental são prioridades de Gestão do Uso da Água. A qualidade e quantidade da água nas nascentes (figura 2) da bacia hidrográfica do Alto Camaquã estão sendo alteradas por fatores de ação antrópica, como o sobrepastoreio das áreas de campo, principalmente em áreas de recarga.

As nascentes são ambientes singulares, com uma complexidade ambiental ainda pouco interpretada. São elementos hidrológicos de importância para a dinâmica fluvial, pois marcam a passagem da água subterrânea para a superficial (FELIPPE, 2009). Assim, é essa a principal importância das nascentes para os sistemas fluviais. As nascentes cumprem papel na perenização destes sistemas, alimentando os córregos e rios com a água armazenada no solo, mesmo em períodos secos. Nascentes são locais onde a água subterrânea aflora através da superfície do solo, formando um curso d'água (PINTO et al., 2003), ou seja, um ponto de recarga dos canais de drenagem das sub-bacias, assim, as nascentes são parcialmente responsáveis pela origem dos recursos hídricos de mais fácil acesso à maioria da população.

Conforme a lei, entre as metas essenciais da política de recursos hídricos, está garantir água para as gerações atual e futura. A proteção das nascentes tem, portanto, um papel de grande importância para a garantia desta meta. Na Lei da Política Nacional dos Recursos Hídricos (PNRH), vale destacar a integração da gestão dos recursos hídricos com a gestão pois o Alto Camaquã tem necessidades interdisciplinares, ou seja, a construção das políticas públicas envolve desde a educação hídrica até ao acesso a água potável.

Outro ponto importante, para a proteção das nascentes, é que a Lei das Águas (BRASIL, 1997), ao estabelecer um regime de outorga de direitos para o uso dos recursos hídricos, declara que, entre os usos que precisam ser outorgados pelo Poder Público, estão a derivação ou captação de uma parte da água de um rio ou outro corpo d'água. Assim, as eventuais captações de águas em nascentes, se forem possíveis, deveriam ser outorgadas. No entanto, a implementação da outorga na realidade do Alto Camaquã impõe, dada a dificuldade de acesso a 
outras fontes de água e à fragilidade sócio-econômica dos pecuaristas familiares, a construção de um processo adaptado, compatível com a realidade regional.

\section{MATERIAIS E MÉTODOS}

A coleta de dados foram efetuadas em vistorias de propriedades de pecuaristas familiares nos Distritos do Barrocão, Alto Bonito e Aberta do Cerro. As nascentes estudadas foram indicadas pelos pecuaristas familiares tendo em vista, tratarem-se das nascentes utilizadas para abastecimento de água o dessedentação animal. A caracterização do regime hídrico das nascentes perenes e não perenes se deu a partir das entrevistas com pecuaristas familiares.

As nascentes foram classificadas no prontuário como nascentes preservadas, perturbadas e degradadas. Segundo Pinto (2003), nascente: Preservadas: é quando apresentam pelo menos 50 metros de vegetação natural no seu entorno medidas a partir do olho d'água em nascentes pontuais ou a partir do olho d'água principal em nascentes difusas; Perturbadas: quando não apresentam 50 metros de vegetação natural no seu entorno, mas apresentam bom estado de conservação, apesar de estarem ocupadas em parte por pastagem e/ou agricultura e Degradadas: quando se encontram com alto grau de perturbação, muito pouco vegetada, solo compactado, presença de gado, com erosões e voçorocas.

A caracterização das nascentes foi avaliada como: difusa: no qual o terreno tem vários olhos de água em um único local e pontual: onde ocorre fluxo de água em um único local. $\mathrm{O}$ modelo elaborado é constituído por um roteiro capaz de orientar e diagnosticar os levantamentos de campo e relevar a importância da preservação das nascentes (Figura 3). Durante o trabalho de campo foram obtidas as coordenadas geográficas e altitudes das respectivas nascentes, utilizando um receptor GPS de navegação, modelo Garmin - GPSmap 76CSx. Foram coletadas amostras de água das nascentes para análise fisico-química. Os frascos foram limpos com detergente alcalino e posteriormente autoclavados. Foi utilizado o uso de EPI's (Luvas) ao coletar as águas das nascentes. As amostras foram transportadas em caixas de isopor com gelo reciclável, com no máximo 48 horas no prazo de chegada ao laboratório.

Os parâmetros utilizados na análise foram: sólidos totais, demanda química e biológica de oxigênio, carbono orgânico total, nitrato e surfactantes. Os valores para estes parâmetros foram obtidos utilizando-se o equipamento de qualidade da água Pastel UV, que é espectrofotômetro portátil, que opera em frequência de ultravioleta, de fácil manuseio e que permite a análise de todos os tipos de água, sejam naturais ou efluentes (SECOMAN, 2010).

Os sólidos totais e demanda química de oxigênio são parâmetros que não estão na portaria 2.914/2011 do Ministério da Saúde e na resolução do Conselho Nacional do Meio Ambiente (CONAMA) - 357. A demanda química de oxigênio é um parâmetro que mede a quantidade de matéria orgânica suscetível de ser oxidada por meios químicos que existam em uma amostra líquida. É um parâmetro que confirma a demanda biológica de oxigênio, que segundo a resolução do CONAMA 357/2005 tem que ser menor que 5,0 mg/l. A relação entre os 
dois parâmetros demanda química de oxigênio e biológica é indicativa de qualidade da água. O nitrato, segundo a portaria 2.914/2011do Ministério da Saúde e segundo a resolução do CONAMA 357/2005, o parâmetro tem que estar menor de $10 \mathrm{mg} / \mathrm{l}$. O surfactante perante a portaria 2914/11 do Ministério da Saúde sua máxima permitida é de 0,5mg/l. (BRASIL, 2005; BRASIL, 2011).

A fim de compreender a relação entre as variáveis levantadas, optou-se por realizar uma análise estatística multivariada. A análise estatística multivariada é uma análise exploratória de dados sobre múltiplas variáveis em um único relacionamento ou conjunto de relações que objetiva a geração de hipóteses sobre os mesmos (HAIR, 2007; VICINI, 2005). A análise estatística multivariada foi efetuada no software Past (SECOMAN, 2012). As análises efetuadas foram: de cluster e de coordenadas principais. A análise de agrupamentos classifica objetos em estudo com base nas características que eles possuem, de modo que objetos similares encontrem-se agrupados na mesma classe (MANLY, 2008; GOTELLI \& ELLISON, 2011). A análise de agrupamento pode ser representada por um dendrograma, que facilita a interpretação dos resultados e a tomada de decisão para a partição dos grupos (PILLAR, 1996; HAIR et al., 2007).

\section{RESULTADOS}

Foram mapeadas 161 nascentes em 56 propriedades de pecuaristas familiares, com uma média de altitude de 165 metros acima do nível do mar. 56\% das nascentes foram difusas e o restante pontual. Na caracterização das nascentes, $68,18 \%$ foram perenes e $31,82 \%$ foram não perenes (Figura 2). No estado de preservação apenas $11 \%$ das nascentes estavam em estado de conservação, 26\% encontravam-se perturbadas por ações antrópicas e 62 \% em nível de degradação, principalmente, pela ação antrópica. Assim, 59\% das nascentes mapeadas eram utilizadas para dessedentação animal e uso doméstico.

Assim a demanda biológica de oxigênio, que representa a matéria orgânica na água, apresentou que 32\% das nascentes estão adequadas à lei e 52,79\% estão acima do permitido. De todas as coletas, em $23 \%$ das nascentes não se puderam obter coletas satisfatórias de água para análise, devido à inviabilidade provocada pelo revolvimento causado pelo pisoteio animal no lodo. Somente uma nascente mostrou-se contaminada por $\mathrm{NO}_{3}$ (nitrato). Apesar de $99 \%$ das amostragens não apresentarem resquícios de $\mathrm{NO}_{3}$, todos os pecuaristas entrevistados afirmaram que o esgoto doméstico é a céu aberto. Nenhuns dos dados apresentados mostraram-se significativos quanto aos surfactantes, oriundos principalmente de detergentes de uso doméstico. A partir deste diagnóstico principal foi feita uma análise multivariada para observar as características das nascentes para entender a relação dos impactos ambientais causados, a partir das unidades amostrais. Utilizou-se o diagrama de cluster, que é um método de agrupamento, que organiza os dados a partir da matriz de dissimilaridade.

Através da análise de ordenação foi possível identificar a distribuição das nascentes no universo amostral e o relacionamento destas com as variáveis observadas a partir dos gráficos de dispersão gerados nos dois programas. A análise de agrupamentos realizada no MULTIV foi 
gerada pela visualização em quatro dimensões do gráfico de dispersão. Observou-se que o diagrama comporta-se em três grandes grupos e foi reafirmado pelo gráfico de coordenadas (Figura 4). Foram utilizados três eixos principais, pois o eixo quatro em diante não são números interpretáveis por ser o Eigenvalue (autovalor) menor que um. Assim o eixo 1, 2 e 3 explicam $46,14 \%$ das variações dos dados.

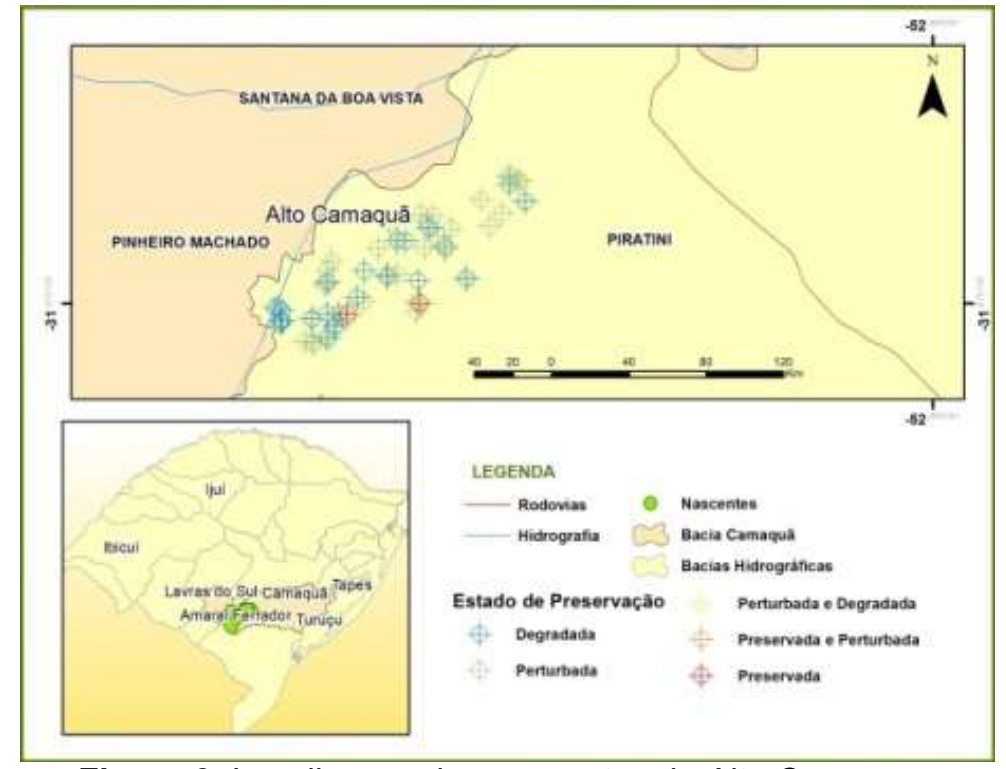

Figura 3: Localização das nascentes do Alto Camaquã.

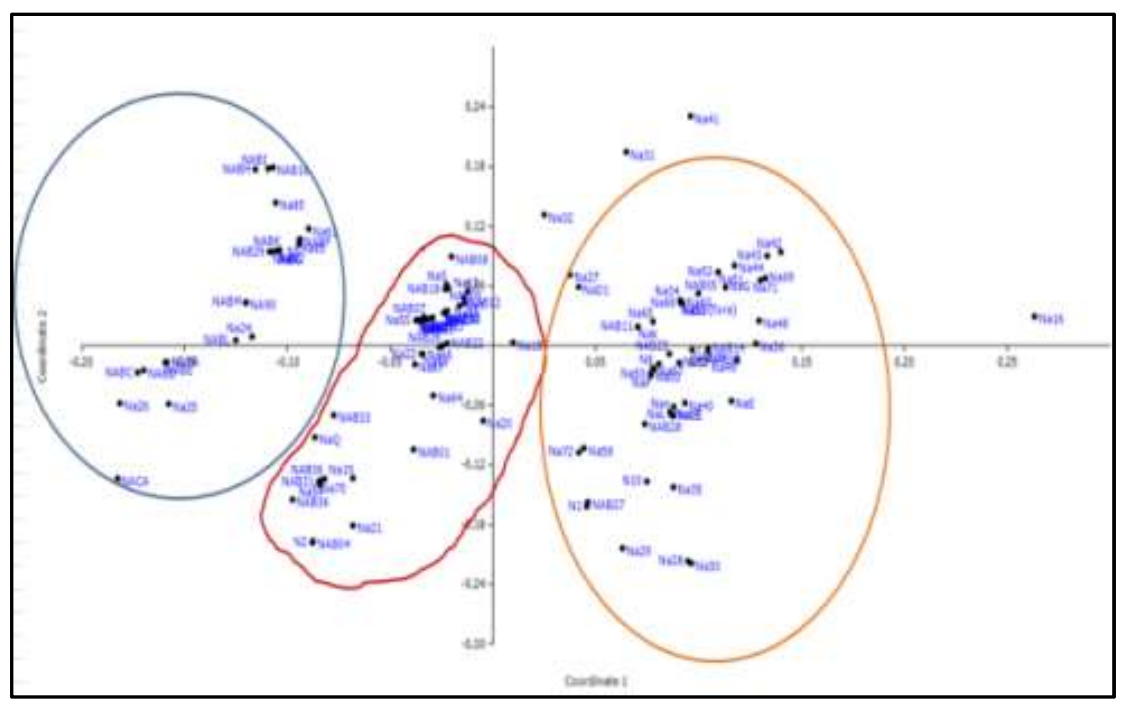

Figura 4: Gráfico de dispersão da análise de coordenadas principais.

Analisando a matriz de dados e o gráfico de dispersão (Gráfico 1) que relaciona as variáveis é possível identificar as relações nas características entre unidades amostrais de cada grupo. O grupo um possui as nascentes com tipologia de afloramento difusa (vários olhos d'água), periodicidade de oferta de água é não perene, ou seja, aflora água em uma estação do ano, grande parte deste grupo, o grau de conservação das nascentes é considerado degradada, o uso da maioria das nascentes é para dessedentação animal. As altitudes das nascentes variam de 122 a 376 a cima do nível do mar. Os parâmetros de qualidade de água não se mostraram 
significativos para a avaliação.

O grupo dois possui as nascentes com tipologia de afloramento difusa, periodicidade de água perene, grande maioria o grau de conservação é Perturbada, $60 \%$ das nascentes deste grupo utilizam as nascentes como dessedentação animal e não necessitam de distribuição de água. A altitude varia de 105 a 229 metros acima do nível do mar. O grupo três obtêm sua tipologia pontual, periodicidade de água perene, o grau de conservação são os três níveis igualitários, visto que, o grau de conservação é preservado, perturbado e degradado. Neste grupo a média de nascentes é de apenas dois afloramentos por propriedade. A grande maioria não é utilizada como bebedouro animal. A altitude varia de 97 á 227 metros a cima do nível do mar.

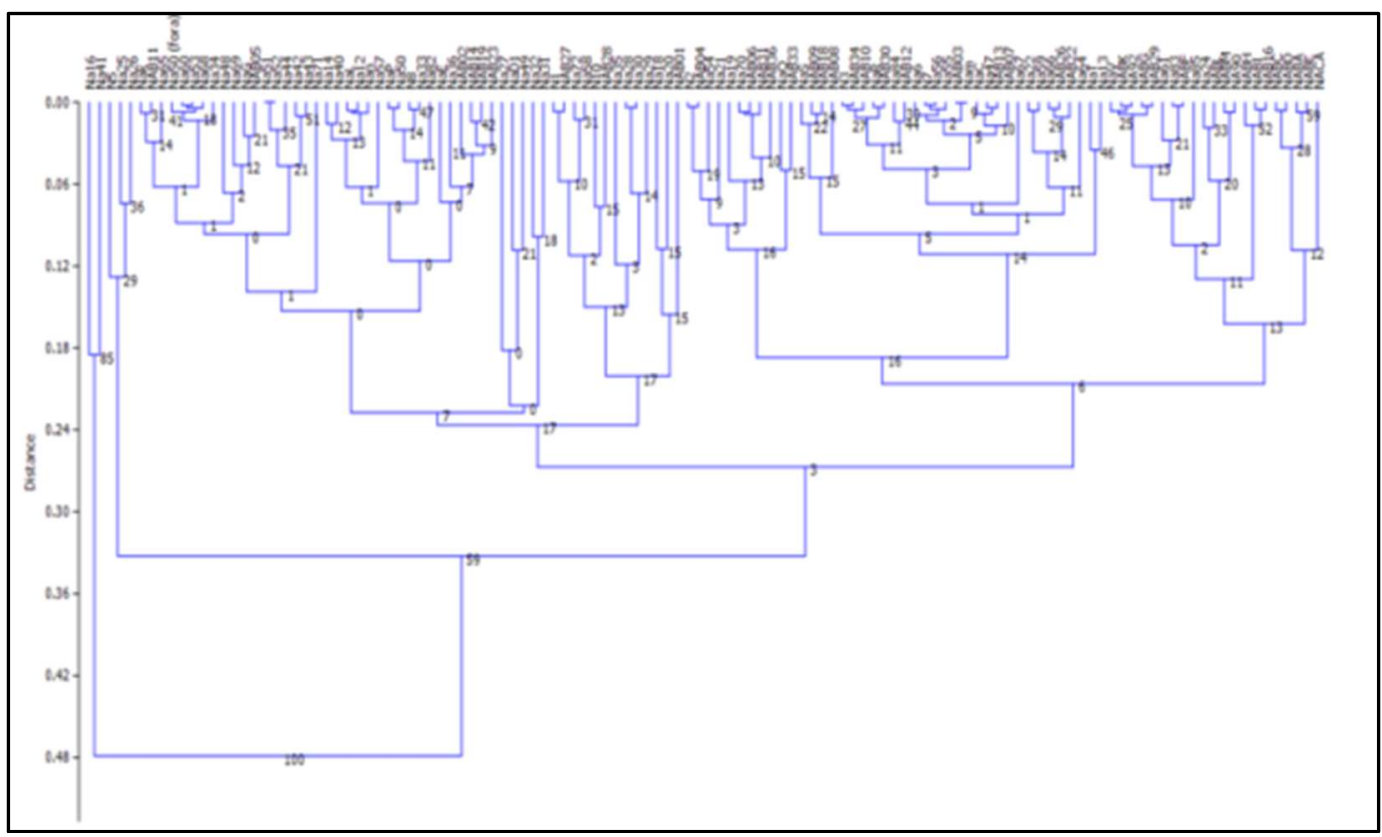

Gráfico 1: Gráfico de dispersão da análise de coordenadas principais.

\section{CONCLUSÕES}

Devido ao "impacto" continuo causado por 150 anos de ocupação do território e segundo a percepção dos pecuaristas familiares, a quantidade de água potável vem diminuindo a cada ano. O diagnóstico aponta para a necessidade de estratégias de educação hídrica endógena, juntamente com programas de recuperação ambiental no contexto da pecuária familiar do Alto Camaquã. A falta de saneamento básico e educação ambiental são os principais fatores de degradação ambiental, pois são áreas com pouco valor econômico e restritivas para agricultura. A educação ambiental na pecuária é um trabalho a ser construído gradativamente, juntamente com forças políticas, pois quebrar ideias, paradigmas e conhecer a realidade dos pecuaristas, ainda é um desafio a ser concedido para futuras estratégias de gestão ambiental para o desenvolvimento territorial.

A água é fator primordial para o sustento à vida. No entanto, o mau gerenciamento pode tornar o recurso escasso, além de comprometer a qualidade. Porém, a dificuldade de informar e educar a sociedade para um problema de dimensão universal é o principal problema, pois, grande 
parte dos seres humanos não acredita que possa perturbar o meio ambiente ao ponto de minorar os recursos naturais disponíveis. Pois revolver o solo, manter campos descobertos de vegetação, queimar ou enterrar resíduos sólidos, manter quantidades de animais elevada em um determinado espaço e captar água das nascentes de forma inadequada por falta de poços é uma realidade que existe em alguns distritos do Território do Alto Camaquã.

Enfatizar os problemas de recursos hídricos na educação proporciona uma base para um pensamento sistêmico, pois a disponibilidade de água em certas regiões do Alto Camaquã é escassa ou mal gerenciada. Observou-se que há falta de água em alguns distritos do território do Alto Camaquã, porém essa escassez é causada principalmente pelo mau gerenciamento e falta de cuidado das fontes de água, ou seja, existem soluções de manejo para que a água da chuva seja aproveitada adequadamente para a subsistência das famílias e produção pecuária.

As nascentes difusas apresentaram o maior grau de degradação, possivelmente por ocorrerem em uma extensão de terra significativa e servirem para dessedentação animal. As nascentes pontuais possivelmente são utilizadas para consumo humano, visto que a implantação de cacimbas pode tornar a nascente degradada. A utilização das formas de caracterização, classificação e parâmetros de qualidade das nascentes em agrupamentos é válida para se obter uma melhor análise do comportamento dos pecuaristas e do território do Alto Camaquã. É uma metodologia útil de avaliação de impacto em nascentes, visto que, há precários estudos nesta região.

\section{REFERÊNCIAS}

BORBA, M. F. S.; TRINDADE, J. P. P.. Desafios para conservação e a valorização da pecuária sustentável. Brasília: Ministério do Meio Ambiente, 2009.

BRASIL. Conselho Nacional do Meio Ambiente. Resolução n 357 de 17 de março de 2005. Dispõe sobre os parâmetros da qualidade da água. Brasília: DOI, 17 Mar 2002.

BRASIL. Lei № 9.433 de 8 de janeiro de 1997. Institui a Política Nacional de Recursos Hídricos, cria o Sistema Nacional de Gerenciamento de Recursos Hídricos, regulamenta o inciso XIX do art. 21 da Constituição Federal, e altera o art. $1^{\circ}$ da Lei $n^{\circ} 8.001$, de 13 de março de 1990, que modificou a Lei $n^{\circ}$ 7.990, de 28 de dezembro de 1989. Brasília: MMA, 8 de Jan 1997.

BRASIL. Ministério da Saúde. Portaria 2.914, de 12 de dezembro de 2011. Dispõe dos parâmetros de potabilidade da água. Brasília: MS, 12 Dez de 2011.

BRASIL. Resolução CONAMA n ${ }^{357}$, de 17 de março de 2005. Dispõe sobre a classificação dos corpos de água e diretrizes ambientais para o seu enquadramento, bem como estabelece as condições e padrões de lançamento de efluentes, e dá outras providências. Brasília: Ministério do Meio Ambiente, 17 de Mar 2005.

CALHEIROS, R. O.; TABAI, F. C. V.; BOSQUILIA, S. V.; CALAMARI, M.. Preservação e Recuperação das Nascentes. Piracicaba: Comitê das Bacias Hidrográficas dos Rios PCJ - CTRN, 2004.

CARVALHO , C. M.. As representações sociais dos pecuaristas famíliares do alto camaquã na construção de uma estratégia de desenvolvimento sustentável. In: Simpósio de Iniciação Científica da Embrapa Pecuária Sul. 2. Anais. São Paulo, 2012

CARVALHO, C. M.. Avaliação das nascentes do território do Alto Camaquã (RS). Congrega: Resumo Simples, 2012. 
FELIPPE, M. F.. Caracterização e tipologia de nascentes em unidades de conservação de Belo Horizonte-MG com base em variáveis geomorfológicas, hidrológicas e ambientais. Dissertação (Mestrado em Geografia e Análise Ambiental) - Universidade Federal de Minas Gerais, Belo Horizonte, 2009.

FIGUEIRÓ, A. S.; SELL, J. C.; LOSEKANN, M. B.; DEGRANDI S. M.. Compreensão da paisagem do Alto Camaquã: debate ambiental sobre o bioma pampa. Mercator, Fortaleza, v.10, n.23, p.147-158, 2011.

GOTELli, N. J.; ElLISON, A. M.. Princípios da estatística em Ecologia. Porto Alegre: Artmed, 2011.

HAIR, J. F. J.; ANDERSON, R. E.; TATHAM, R. L.; BLACK, W. C.. Análise multivariada de dados. Porto Alegre: Bookman, 2007.

KIRCHHEIM, R. E.; AGRA, S. G.. Diagnóstico hidrogeológico do Estado do RS: uma ferramenta para o plano estadual de recursos hídricos. In: SIMPÓSIO BRASILEIRO DE RECURSOS HÍDRICOS, 19. Anais. Maceió: ABRH, 2011.

LUCAS, A. S.. Caracterização de nascentes no território do Alto Camaquã e a conservação ambiental no contexto da pecuária familiar. São Gabriel: Universidade Federal do Pampa, 2013.

MANLY, B. J. F.. Métodos estatísticos multivariados. Porto Alegre: Bookman, 2008.

PILLAR, V. P.; ORLOCI, L.. On randomization in vegetation science: multifactor comparisons of relevé groups. Uppsala, v.7, p.585-595, 1996.

PINTO, L. V. A.. Caracterização física da sub-bacia do Ribeirão Santa Cruz, Lavras, MG, e propostas de recuperação de suas nascentes. Dissertação (Mestrado em Engenharia Florestal) - Universidade Federal de Lavras, Lavras: UFLA, 2003.

REBOUÇAS, A. C.. Água e desenvolvimento rural. Instituto de Estudos Avançados, São Paulo, n.43, v.15, 2001.

RIO GRANDE DO SUL. Lei 10.350, de 30 de dezembro de 1994. Institui o Sistema Estadual de Recursos Hídricos, regulamentando o artigo 171 da Constituição do Estado do Rio Grande do Sul. Porto Alegre: SEIRH, 30 Dez 1994.

ROCHA, J. M.. As Raízes Da Crise Da Metade Sul: Estudo Da Formação Econômica Do Rio Grande Do Sul. Ed: Fundação Universidade Federal Do Pampa, 2011.

SEMA. Secretaria Estadual do Meio Ambiente. Comitês de gerenciamento de bacia hidrográfica. Brasília: DOU, 2010.

TRINDADE, J. P. P.; BORBA M. F. S.; LEFEVBRE, J.. Território do Alto Camaquã: apresentação da cobertura vegetal do Alto Camaquã: junho de 2007. Bagé: Embrapa Pecuária Sul, 2010b.

TRINDADE, J. P. P.; BORBA, M. F. S.; LEFEVBRE, J.. Vegetação do território do Alto Camaquã: obtenção, tratamento e classificação de imagens de satélite LandsatTM. Bagé: Embrapa Pecuária Sul, 2010.

VICINI, L.. Análise multivariada da teoria à prática. Santa Maria: CNNE, 2005. 